EXTENDED REPORT

\title{
Falls and health status in elderly women following first eye cataract surgery: a randomised controlled trial
}

\author{
R H Harwood, A J E Foss, F Osborn, R M Gregson, A Zaman, T Masud
}

Br J Ophthalmol 2005;89:53-59. doi: 10.1136/bjo.2004.049478

See end of article for authors' affiliations

Correspondence to:

Correspondence to:
Rowan Harwood or Alexander Foss, University Hospital, Queen's Medical Centre, Nottingham NG7 $2 \mathrm{UH}$, UK; rowan. harwood@ntlworld.com or alexander.foss@btinternet. com

Accepted for publication 27 June 2004
Background/aim: A third of elderly people fall each year. Poor vision is associated with increased risk of falls. The authors aimed to determine if first eye cataract surgery reduces the risk of falling, and to measure associated health gain.

Methods: 306 women aged over 70, with cataract, were randomised to expedited (approximately 4 weeks) or routine (12 months wait) surgery. Falls were ascertained by diary, with follow up every 3 months. Health status was measured after 6 months.

Results: Visual function improved in the operated group (corrected binocular acuity improved by 0.25 logMAR units; $8 \%$ had acuity worse than $6 / 12$ compared with $37 \%$ of controls). Over 12 months of follow up, $76(49 \%)$ operated participants fell at least once, and $28(18 \%)$ fell more than once. $69(45 \%)$ unoperated participants fell at least once, $38(25 \%)$ fell more than once. Rate of falling was reduced by $34 \%$ in the operated group (rate ratio $0.66,95 \%$ confidence interval 0.45 to $0.96, p=0.03$ ). Activity, anxiety, depression, confidence, visual disability, and handicap all improved in the operated group compared with the control group. Four participants in the operated group had fractures (3\%), compared with $12(8 \%)$ in the control group $(p=0.04)$.

Conclusion: First eye cataract surgery reduces the rate of falling, and risk of fractures and improves visual function and general health status.
$\mathrm{F}$ alls among elderly people are common and serious. One third of the population over 65 years old fall at least once each year, rising to over half for 85 year olds living at home, and higher still for those in institutional care. ${ }^{12}$ Falls frequently lead to hospital admission. About $10-20 \%$ of falls lead to injury, 5-6\% result in fractures, and $1 \%$ cause hip fractures. ${ }^{3-5}$

A number of potentially modifiable risk factors for falling and fractures have been identified. ${ }^{126-8}$ These include prevention and treatment of osteoporosis, muscle weakness, use of neuroleptic medications, and impairment of balance. Multifactorial intervention can reduce falling by 30-50\%. ${ }^{10}$ However, evidence for the effectiveness of interventions to reduce falls remains patchy. ${ }^{11}$

Many studies have shown that poor vision is an independent risk factor for falls, with a risk ratio around two $.^{6-8} 12-18$ Visual acuity, contrast sensitivity, stereopsis, and visual field defects have all been implicated as important features. The commonest cause of poor vision in elderly people is cataract. Cataract surgery improves visual function. ${ }^{19}$ Modern techniques (using phacoemulsification) result in rapid visual improvement, with $50 \%$ of patients getting good vision by 24 hours and $96-99 \%$ by 4 weeks. The majority get good distance vision without the need for glasses.

We aimed to see if cataract surgery, using this technique, resulted in a reduction in the incidence of falls. We measured health gain associated with surgery, using comparisons made with a "waiting list" control group.

\section{METHODS}

\section{Participants}

The study population was women aged over 70, with cataract, referred to one of three consultant ophthalmologists (or to an optometrist led cataract clinic when this was established in 2001), who were suitable for surgery, and who had not had previous ocular surgery. We excluded women with cataract not suitable for surgery by phacoemulsification (Fuchs' corneal dystrophy, active intraocular inflammation, lens zonule dehiscence, or lens instability); those with severe refractive error in the second eye $(>+4.00$ or $<-6.00 \mathrm{DS}$, because of the risk of postoperative anisometropia); those with visual field defects, severe co-morbid eye disease affecting visual acuity; those registrable partially sighted as a result of cataract (who would have early surgery arranged routinely); and those with memory problems preventing the completion of the lengthy questionnaires or reliable recall of falls. All participants gave informed, written consent. Ethical committee approval for the study was granted.

Participants were recruited during a routine clinic visit where the study was explained and a written information sheet given. Formal consent was gained, and baseline assessment and treatment allocation made by a research nurse (FO) 1-2 weeks later.

\section{Randomisation}

Participants were randomised to either expedited surgery (target within 1 month), or routine surgery (a "waiting list" control group, target surgery within 13 months, or the routine waiting time when this became less than 13 months). Randomisation was from lists prepared (by $\mathrm{RH}$ ) from random numbers, in variably sized, permuted blocks to maintain approximate equality in the size of the groups. Allocation was concealed in sequentially numbered, opaque, sealed, envelopes which were opened after consent was obtained and baseline assessment made. Those patients not receiving early surgery were offered an up to date spectacle prescription.

\section{Surgery}

Patients had small incision cataract surgery and implantation of a folding silicone intraocular lens under local anaesthetic (one patient had a general anaesthetic). There were minor

Abbreviations: HADS, Hospital Anxiety and Depression Scale; LHS, London Handicap Scale; MMSE, Mini Mental State Examination 


\begin{tabular}{|c|c|c|c|}
\hline & Team A & Team B & Team C \\
\hline Number of cases & 81 & 45 & 24 \\
\hline Surgical approach & $\begin{array}{l}\text { Temporal clear } \\
\text { cornea }\end{array}$ & $\begin{array}{l}\text { Superior clear } \\
\text { cornea }\end{array}$ & $\begin{array}{l}\text { Temporal clear } \\
\text { cornea }\end{array}$ \\
\hline $\begin{array}{l}\text { Mean phacoemulsification time } \\
\text { (seconds) }\end{array}$ & 67 & 67 & 67 \\
\hline Paracentesis stitched & 2 & 0 & 0 \\
\hline Section stitched & 0 & 0 & 1 \\
\hline Iris hooks & 0 & 1 & 1 \\
\hline Iris damage & 0 & 2 & 1 \\
\hline Posterior capsular rupture & 0 & 5 & 0 \\
\hline Anterior vitrectomy performed & 0 & 2 & 0 \\
\hline $\begin{array}{l}\text { Posterior capsular opacification } \\
\text { noted at } 6 \text { months }\end{array}$ & 2 & 0 & 1 \\
\hline $\begin{array}{l}\text { YAG capsulotomy performed } \\
\text { during study period }\end{array}$ & 2 & 0 & 1 \\
\hline
\end{tabular}

differences between the surgical approaches employed by the three teams (table 1). All had refraction and assessment of their vision at 4 weeks.

\section{Measurements}

Baseline information was collected on history of falls, risk factors for falls, co-morbid diagnoses, drugs taken, and social support. ${ }^{20}$ A battery of health status measures was applied including cognitive function (Mini Mental State Examination, $\left.\mathrm{MMSE}^{21}\right)$; activity ${ }^{22}$; anxiety and depression (Hospital Anxiety and Depression Scale, HADS ${ }^{23}$ ); confidence (falls efficacy scale ${ }^{24}$ ); activities of daily living (Barthel Inde ${ }^{25}$ ); visual disability (VF-14 $\left.{ }^{26}\right)$; handicap (London Handicap Scale, LHS, interview version ${ }^{27}$ ); and overall quality of life (Euroqol ${ }^{28}$ ).

Ophthalmic history included the use of glasses and presence of other ocular problems. Examination included visual acuity (unaided, with current spectacles, and with pinhole, recorded as the logarithm of the minimum angle resolvable, logMAR, using an EDTRS-modified Bailey-Lovie chart $^{29}$; Precision Vision, Villa Park, IL, USA); contrast sensitivity using a Pelli-Robson chart $^{30}$ (Clement Clarke, Harlow, UK); stereopsis using the Frisby system and the Wirt Fly (Clement Clarke), which together measure down to 150 seconds of arc; presence of normal oculomotility; visual fields (by confrontation); and full ocular examination (including fundal examination through dilated pupils).

A fall was defined as unintentionally coming to rest on the ground or at a lower level, with or without loss of consciousness. Participants were asked to record falls in a diary, and were telephoned at 3 and 9 months, and interviewed at 6 and 12 months, to record the dates of falls, and utilisation of health and social services, and informal care. Six months after randomisation, participants were interviewed to complete the anxiety, depression, activity, confidence, activities of daily living, visual disability, handicap, and quality of life questionnaires. Ophthalmological examination was repeated 1 month after surgery, and 6 months and 12 months after randomisation.

Assessment (after baseline assessment) was not masked to allocation.

\section{Sample size}

The expected prevalence of falls was $50 \%$. A one third reduction in participants falling, giving a difference of $16 \%$ between the two groups, was taken to be clinically significant. To have an $80 \%$ chance of detecting this at $95 \%$ confidence required 160 patients in each arm giving a trial size of 320 .

\section{Statistical analysis}

All analyses were by intention to treat. The pre-planned primary end points were time to first fall (or death), and time to second fall (or death), defining recurrent fallers. Cox proportional hazards regression analysis was used to generate hazard curves for risk of falling, to estimate relative risk, and to adjust for baseline imbalances between groups. Participants withdrawing or having out of trial early surgery were censored. We compared the rate of falling (total number of falls/number of days in the trial) using negative binomial regression. We also compared the proportions of participants experiencing fractures.

Analyses were repeated for participants with baseline vision worse than $6 / 12$, and for participants who reported falling in the year before randomisation. These analyses were exploratory to see if benefits were confined to, or were greater in, relevant clinically identifiable subgroups.

Health gain was assessed by comparing changes in visual functions, activity, anxiety, depression, confidence, disability, handicap, and quality of life measures between operated and control groups using linear regression to adjust for baseline imbalances. This yields a more precise comparison than crude scores alone, and corrects for regression to the mean. The relative size of differences in health status measures was compared using the effect size (mean change/initial standard deviation). ${ }^{31}$

\section{Role of the funding source}

The funders had no role in the conduct, analysis, or reporting of the study.

\section{RESULTS}

We randomised 154 participants to expedited surgery and 152 to routine surgery, between 1999 and 2002. Four patients died, 13 (5\%) withdrew or were lost, and $15(5 \%)$ had surgery outside the trial (fig 1); 12 of these experienced a fall before being lost (and so contribute to the analysis). Median time from randomisation to expedited surgery was 27 days (range 1-212), and time to routine surgery was 337 days (range 133-485). Unintended delays were all caused by ill health.

At baseline the two groups were reasonably well matched (tables 2 and 3). Participants in the expedited operation group had marginally less good general health, but marginally better visual function, including stereopsis and visual acuity. Participants with poor vision (Snellen acuity worse than 6/12) were $37(24 \%)$ in the expedited group, and 47 $(31 \%)$ in the control group, although median acuity and contrast sensitivity were similar between groups. About half reported falling in the previous 12 months. 


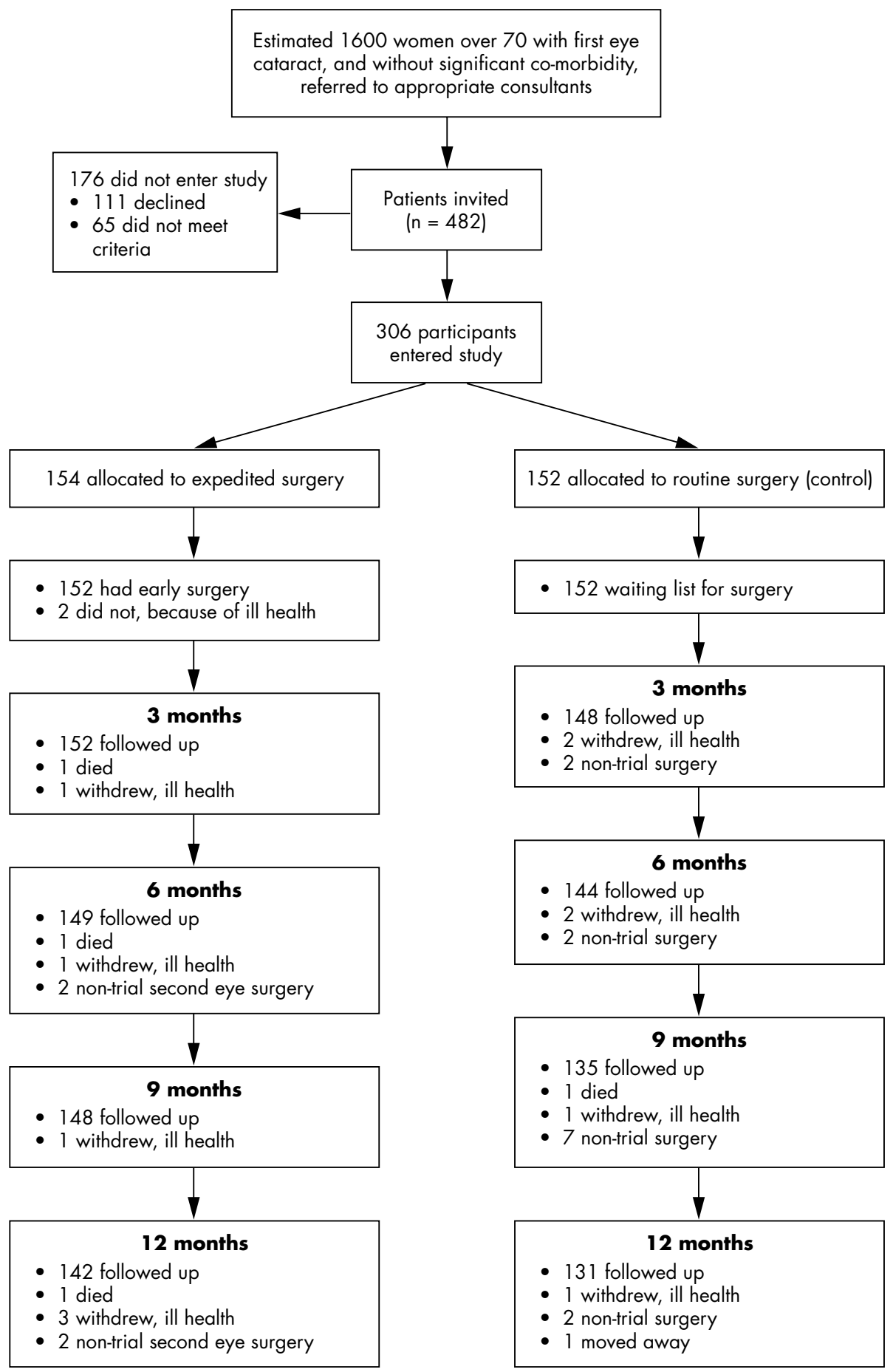

After surgery, refractive outcomes were satisfactory. The mean best sphere equivalent was $-0.22 \mathrm{DS}$ (standard deviation 1.0), and was similar between surgical teams, as was astigmatism (mean 0.86DC, standard deviation 0.9). Complication rates were low (table 1), with five posterior capsule ruptures, two of which required anterior vitrectomies. All cases had a folding posterior chamber lens inserted at the time of surgery and none required a second surgical procedure.

In all, 352 falls were recorded among 145 participants. 76 (49\%) expedited patients fell compared with 69 (45\%) control patients. Hazard ratio for any falls was 0.95 (95\% confidence interval 0.69 to 1.35 ), $\log$ rank test $0.08,1 \mathrm{df}, \mathrm{p}=0.77$ (fig 2).
Figure 1 Trial profile. ( $18 \%)$ expedited patients fell twice or more, compared with $38(25 \%)$ control patients. Hazard ratio was $0.60 \quad(95 \%$ confidence interval $0.36-0.98), \log$ rank test $4.3,1 \mathrm{df}, \mathrm{p}=0.04$ (fig 3).

Statistically adjusting the relative risk of falling for history of falls in the past 1 and 12 months; history of stroke, heart or chest disease; poor visual acuity; reported postural dizziness; and baseline handicap and confidence, or, separately, for activity level at 6 months, had no effect on the results. Confining analysis to those with visual acuity worse than 6/12 at baseline had no effect on the results. Analysis restricted to the 155 participants who reported falling in the 


\begin{tabular}{|c|c|c|c|c|}
\hline & \multicolumn{2}{|c|}{$\begin{array}{l}\text { Expedited group } \\
(n=154)\end{array}$} & \multicolumn{2}{|c|}{$\begin{array}{l}\text { Routine group } \\
(n=152)\end{array}$} \\
\hline & Median & Range & Median & Range \\
\hline Age (years) & 78.8 & $70-95$ & 78.1 & $70-90$ \\
\hline Days from referral to clinic appointment & 92 & $0-354$ & 101 & $0-494$ \\
\hline Days from clinic appointment to operation & 42 & $7-220$ & 350 & $143-493$ \\
\hline Number of co-morbid diagnoses & 8 & $5-11$ & 8 & $4-10$ \\
\hline Number of drugs & 4 & $0-15$ & 3.5 & $0-15$ \\
\hline Social support deficits/ 6 & 1 & $0-3$ & 0 & $0-5$ \\
\hline Mini mental state $/ 30$ & 27 & $15-30$ & 27 & $18-30$ \\
\hline Activity scale & 4.7 & $0.1-27.3$ & 4.6 & $0.4-30.6$ \\
\hline HADS anxiety/28 & 7 & $0-18$ & 6 & $0-19$ \\
\hline HADS depression $/ 28$ & 4 & $1-14$ & 4 & $0-16$ \\
\hline Barthel index $/ 20$ & 18 & $10-20$ & 19 & $15-20$ \\
\hline Confidence (FES)/30 & 90 & $23-100$ & 93 & $73-100$ \\
\hline Euroqol/1.0 & 0.73 & $-0.06-1.0$ & 0.77 & $-0.08-1.0$ \\
\hline London Handicap Scale/100 & 83.9 & $47-100$ & 86.2 & $50-100$ \\
\hline Visual disability VF-14/100 & 79.5 & $38-100$ & 82.5 & $43-100$ \\
\hline Corrected visual acuity (logMAR) & 0.28 & $-0.06-0.96$ & 0.28 & $-0.08-0.94$ \\
\hline Unaided acuity (logMAR) & 0.50 & $0.0-1.36$ & 0.54 & $0.04-1.32$ \\
\hline Pinhole acuity (logMAR) & 0.20 & $0-0.6$ & 0.20 & $-0.18-0.70$ \\
\hline Contrast sensitivity (Pelli-Robson, dB) & 1.35 & $0.35-1.95$ & 1.35 & $0.05-1.80$ \\
\hline
\end{tabular}

12 months before randomisation gave a statistically uncertain $20 \%$ reduction in first falls during the study period in the operated group (hazard ratio $0.80,95 \%$ confidence interval 0.5 to $1.3, \mathrm{p}=0.4$ ).

Rate of falling was $1.00 / 1000$ patient days in the operated group and 1.52/1000 patient days in the control group. The rate ratio was 0.66 (95\% confidence interval 0.45 to 0.96 , $\mathrm{p}=0.03$, by negative binomial regression). The main effect was an approximate halving of falls in participants who fell more than three times per 1000 patient days (that is, more than about once a year).

Six months after randomisation (median 185 days, range 126-256) the operated group reported statistically significant benefits in visual acuity, contrast sensitivity, stereopsis, activity, anxiety, depression, confidence, visual disability, handicap, and Euroqol quality of life compared with the control group (tables 4 and 5). These differences comprised small improvements between baseline and 6 months for the operated group, and deteriorations in the control group. By 6 months the number of patients with corrected binocular vision worse than $6 / 12$ was $12(8 \%)$ in the expedited group and $52(37 \%)$ in the control group. Effect sizes for the changes were very large $(>1)$ for visual acuity and visual disability, large $(>0.8)$ for contrast sensitivity, moderate $(0.5-0.8)$ for handicap, and small $(<0.5)$ for the other measures.
Four participants (3\%) in the operated group had a fracture (three wrist, one other (non-hip) leg), compared with 12 $(8 \%)$ in the control group (one hip, one other leg, four neck of humerus, four wrist, four other arm, two other-some had more than one). Risk ratio was 0.33 (95\% confidence interval 0.1 to 1.0 , Fisher's exact test, $\mathrm{p}=0.04$ ).

\section{DISCUSSION}

We demonstrated that first eye cataract surgery is associated with large gains in visual function, and reduced visual disability. We also showed that these changes are accompanied by improvements in activity, anxiety and depression, confidence, handicap, and quality of life. We were unable to demonstrate a reduction in the risk of a first fall during the 1 year follow up period, but there was a $40 \%$ reduction in the risk of recurrent falls, a $34 \%$ reduction in the overall rate of falling, and a reduction in the fracture risk. There may have been a reduction in "first" falls among participants reporting a fall in the year before randomisation, although our study was too small to be sure of this.

The population studied was frail (with a median of eight co-morbid diagnoses and five prescription drugs), but performed well in basic activities of daily living as measured on the Barthel Index. Half the participants reported falling in the year before randomisation, and half fell during follow up. At baseline three quarters of participants had corrected vision

Table 3 Baseline characteristics in expedited and routine surgery groups

\begin{tabular}{lccccc}
\hline & \multicolumn{2}{c}{ Expedited group } & & \multicolumn{2}{c}{ Routine group } \\
\cline { 2 - 3 } \cline { 5 - 6 } \cline { 5 - 6 } & No & $\%$ & & No & $\%$ \\
\hline Falls in last 12 months & 79 & 51 & 72 & 47 \\
Falls in last month & 17 & 11 & & 16 & 11 \\
Lives alone & 96 & 63 & & 88 & 58 \\
Seen GP in last month & 78 & 51 & & 76 & 50 \\
Heart problem & 48 & 31 & & 36 & 24 \\
Chest problem & 24 & 16 & & 42 & 27 \\
Arthritis & 119 & 77 & 118 & 78 \\
Stroke & 15 & 9.7 & 11 & 7.2 \\
Previous fracture (any) & 71 & 46 & & 68 & 45 \\
Postural dizziness & 60 & 39 & & 56 & 37 \\
Postural hypotension & 30 & 20 & 26 & 17 \\
Car drivers & 14 & 9 & 17 & 11 \\
\hline
\end{tabular}




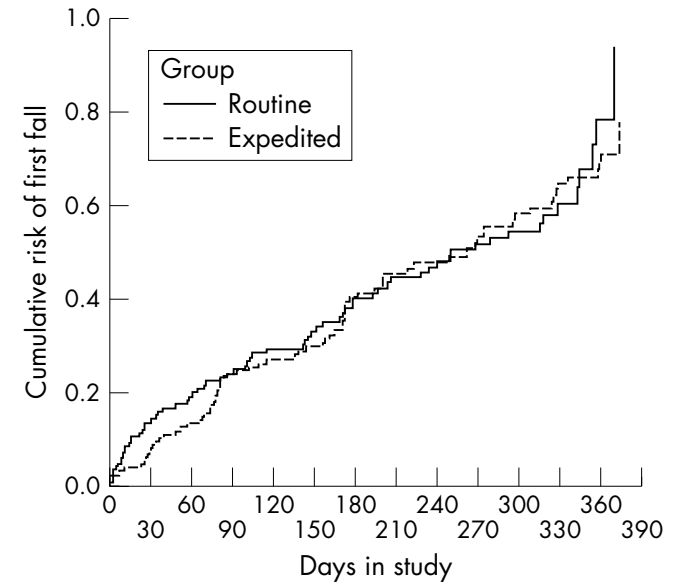

Numbers at risk

$\begin{array}{rrrrrr}\text { Operated } & 154 & 119 & 97 & 85 & 62 \\ \text { Control } & 152 & 117 & 95 & 79 & 15\end{array}$

Figure 2 Cumulative risk of first falls.

better than the driving standard, which reflects current referral patterns for patients with cataract. All aspects of visual function and health status deteriorated in the control group over the year of follow up, demonstrating that cataract surgery has a role in maintaining, as well as improving, vision.

The falls literature draws a distinction between "single" and "recurrent" fallers (over a period of about a year). ${ }^{132}$ Single, or sporadic, falls will often be accidental trips related to activity. Single (or more accurately "infrequent") fallers are often more similar to never fallers than recurrent fallers, so there is a rationale for considering recurrent falls separately. Recurrent (or frequent) fallers have more risk factors for falling, more adverse physiological parameters (contrast sensitivity, reaction time, body sway, quadriceps strength, and vibration sensation), ${ }^{14}$ and are at high risk of adverse consequences.

It is possible that an increase in activity (reflected in the improved activity and confidence that we measured) could have offset improvements in stability caused by better vision, resulting in more falls after surgery. However, our results were robust to statistical adjustment for this. It is also possible that the baseline vision in this population was too good to reduce the risk of falls by surgery. At baseline visual function was reasonable in most participants, despite a symptomatic cataract. However, large cohort studies show a graded relation between acuity and falls risk, with no threshold level..$^{13}$ Moreover, we demonstrated good improve-

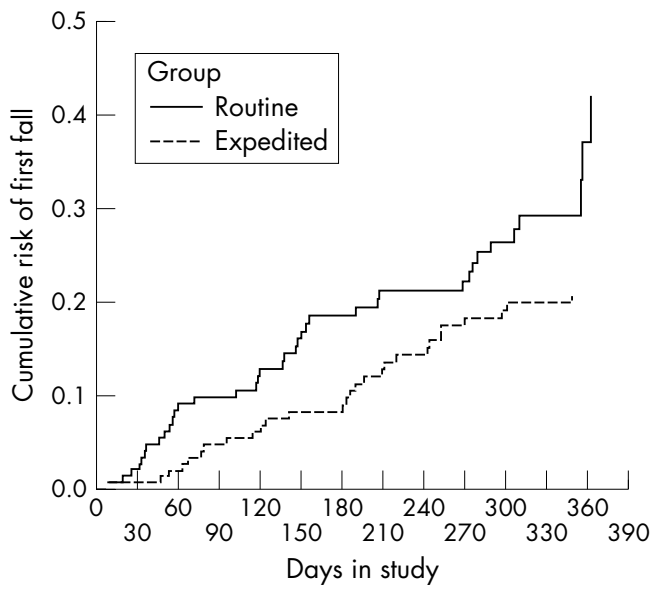

Numbers at risk

$\begin{array}{rccccc}\text { Operated } & 154 & 144 & 135 & 123 & 102 \\ \text { Control } & 152 & 134 & 115 & 98 & 21\end{array}$

Figure 3 Cumulative risk of second falls.

ments in visual function and visual disability after surgery compared with controls. We considered it unethical to deny early surgery to patients with very poor visual function.

One previous (before and after) study reported a large reduction in falls after cataract surgery (odds ratio 0.08 ). Thirty one of 84 patients fell over the 6 months before surgery. Only six of these fell in the 6 months after surgery, along with two who had not previously fallen. ${ }^{33}$ We have no easy explanation for the difference between these results and ours.

When this study was designed we noted a surprising disparity between demand for an apparently highly successful operation and its availability in the British health service, resulting in waiting times of $12-15$ months in Nottingham at the time. One explanation was the absence of robust health gain data which would allow prioritisation against other interventions. We have used a multilevel approach to assessing health gain.

Basic visual functions (acuity, contrast sensitivity) are closely related to the physiology of the eye, and it is easy to demonstrate large improvements after surgery to remove a cataract and insert a prosthetic lens. Improvements in stereopsis, a binocular function, are probably explained by the second eye having sufficient function to permit improved stereopsis once the first cataract was removed.

The visual disability scale comprised items describing limitations in activities requiring vision (recognising people, reading, cooking, playing games, driving). Activity limitation

\begin{tabular}{|c|c|c|c|c|}
\hline \multirow{2}{*}{$\begin{array}{l}\text { Stereopsis } \\
\text { (sec arc) }\end{array}$} & \multicolumn{2}{|c|}{ Expedited } & \multicolumn{2}{|c|}{ Routine } \\
\hline & No & $\%$ & No & $\%$ \\
\hline \multicolumn{5}{|l|}{ Baseline } \\
\hline 150 & 93 & 60 & 78 & 51 \\
\hline 300 & 30 & 20 & 33 & 22 \\
\hline 600 & 9 & 6 & 14 & 9 \\
\hline$>600$ Wirt able & 12 & 8 & 11 & 7 \\
\hline$>600$ Wirt unable & 10 & 7 & 16 & 11 \\
\hline $\begin{array}{l}\text { o monin } \\
150\end{array}$ & 108 & 73 & 58 & 41 \\
\hline 300 & 22 & 15 & 35 & 25 \\
\hline 600 & 8 & 5 & 18 & 13 \\
\hline$>600$ Wirt able & 9 & 6 & 14 & 10 \\
\hline$>600$ Wirt unable & 1 & 1 & 15 & 11 \\
\hline
\end{tabular}


Table 5 Comparison of changes in health status from baseline for participants completing 6 month assessments

\begin{tabular}{|c|c|c|c|c|c|c|c|}
\hline \multirow[b]{3}{*}{ Outcome } & \multicolumn{2}{|c|}{$\begin{array}{l}\text { Expedited surgery first eye } \\
(n=148)\end{array}$} & \multicolumn{2}{|c|}{$\begin{array}{l}\text { Unoperated first eye } \\
\text { (control) }(n=140)\end{array}$} & \multicolumn{3}{|c|}{$\begin{array}{l}\text { Difference between expedited and control } \\
\text { (adjusted for baseline values) }\end{array}$} \\
\hline & \multirow{2}{*}{$\begin{array}{l}\text { Baseline } \\
\text { Mean }\end{array}$} & \multirow{2}{*}{$\begin{array}{l}6 \text { months } \\
\text { Mean }\end{array}$} & \multirow{2}{*}{$\begin{array}{l}\text { Baseline } \\
\text { Mean }\end{array}$} & \multirow{2}{*}{$\begin{array}{l}6 \text { months } \\
\text { Mean }\end{array}$} & \multirow[b]{2}{*}{ Mean } & \multirow[b]{2}{*}{$95 \% \mathrm{Cl}$} & \multirow[b]{2}{*}{ p Value } \\
\hline & & & & & & & \\
\hline Activity & 6.7 & 7.2 & 7.1 & 6.5 & 1.1 & 0.01 to 2.1 & 0.05 \\
\hline Confidence & 82.3 & 83.2 & 85.0 & 80.3 & 5.4 & 2.7 to 8.0 & $<0.0005$ \\
\hline HADS Anxiety & 7.2 & 6.5 & 6.9 & 7.4 & -0.9 & -0.3 to -1.6 & 0.007 \\
\hline HADS Depression & 4.6 & 4.2 & 4.5 & 5.1 & -0.8 & -0.3 to -1.3 & 0.003 \\
\hline Barthel Index & 18.4 & 18.4 & 18.9 & 18.9 & 0.1 & -0.2 to 0.3 & 0.6 \\
\hline VF-14 visual disability & 78.5 & 90.6 & 80.3 & 74.4 & 17.3 & 14.5 to 20.2 & $<0.0005$ \\
\hline London Handicap Scale & 82.1 & 85.0 & 84.1 & 79.9 & 6.6 & 4.5 to 8.7 & $<0.0005$ \\
\hline Euroqol & 0.70 & 0.73 & 0.70 & 0.67 & 0.06 & 0.01 to 0.11 & 0.02 \\
\hline Unaided VA & 0.51 & 0.22 & 0.56 & 0.56 & -0.32 & -0.27 to -0.36 & $<0.0005$ \\
\hline Spectacles VA & 0.30 & 0.10 & 0.29 & 0.35 & -0.25 & -0.22 to -0.29 & $<0.0005$ \\
\hline Pinhole VA & 0.21 & 0.09 & 0.22 & 0.26 & -0.17 & -0.14 to -0.19 & $<0.0005$ \\
\hline Contrast sensitivity (dB) & 1.37 & 1.55 & 1.39 & 1.33 & 0.23 & 0.18 to 0.27 & $<0.0005$ \\
\hline Depth perception/5 point scale & 1.71 & 1.47 & 2.03 & 2.24 & 0.62 & 0.41 to 0.83 & $<0.0005$ \\
\hline
\end{tabular}

(disability) is, however, the final common pathway for other problems, such as hand function, cognition, and to some extent, opportunity, so untreated co-morbidity might reduce the impact of improved vision on disability. In practice, large reductions in "disease specific" disability resulted from surgery.

In order to compare this intervention with others, we must measure on generic scales as well. We used the Euroqol and London Handicap Scale. The Euroqol is a brief five item questionnaire covering mobility, self care and other activities, pain, anxiety, and depression. Responses are weighted to give a utility score (reflecting the absolute value or worth of a state of health). Although we did demonstrate changes on this scale, they were small in magnitude, and suggest that this scale is insufficiently sensitive to change for this intervention (by virtue of its content). The London Handicap Scale is based on responses to six items defined by the WHO handicap classification-mobility, physical independence, occupation, awareness, social integration, and economic self sufficiency. ${ }^{34}$ This has since been reworked as "participation," ${ }^{35}$ and is defined as disability at the level of the person in context (what someone can do given their physical and social circumstances). It is also weighted as a utility score, and proved more responsive to change. We also showed changes in "intermediate" outcomes of affect, activity (measured by questionnaire as estimates of energy expended), and confidence.

Health gain from cataract surgery remains important from a health policy perspective. The prevalence of cataract in older people is very high. ${ }^{36-38}$ Age specific prevalence of acuity impairing cataract in North London at age 65-70 was $17 \%$, of which $11 \%$ were unoperated. At age $80-84$ this was 55\%, of which $49 \%$ were unoperated. This potentially represents a huge "health need," and could overwhelm ophthalmology services. In the United Kingdom there is continuing pressure to reduce waiting times for elective surgery, which might raise questions about the level of visual impairment that justifies the offer of cataract surgery. We present data demonstrating an unequivocal benefit from surgery, which justifies offering surgery to all patients who present, even with "mild" cataracts.

Our study had some limitations, especially representativeness. Surgical trials are difficult to undertake. Recruitment was slower than we anticipated. A quarter of invited participants declined to take part. We found it hard to persuade optometrists running an optometrist led cataract clinic to refer patients to the trial. Waiting times for surgery fell rapidly during the trial, following UK government policy on improved access to elective surgery. Final follow up before 12 months in some cases reflected this.

There is no reason to believe that surgery would be any less beneficial in people with more visually impairing cataract than we studied. We cannot be sure about benefits in people with "asymptomatic" cataracts (for example, detected during screening for falls risk factors). Currently, many cataracts are diagnosed by optometrists during what amounts to screening examinations, and there is no reason to believe that improvements in visual function would be any less in these cases. On a balance of probabilities our results should apply to anyone with a diagnosable cataract.

Previous falls prevention intervention studies, ${ }^{9}$ and falls guidelines, ${ }^{39}$ recommend identifying subjective visual problems, making a diagnosis, and intervening as appropriate (mainly referral for new spectacles or cataract surgery). This remains good advice. First eye cataract surgery clearly improves quality of life, and reduces falls among the subgroup prone to frequent falls. Our study suggests that waiting for cataract surgery is detrimental to health, and that patients who fall while awaiting surgery should have their procedure expedited. We suggest that assessment of patients with falls should routinely include vision, including ophthalmoscopy to detect cataract, even when no visual problem is reported by the patient.

\section{CONTRIBUTORS}

AF conceived the study, wrote the protocol, recruited patients, performed operations, managed the project, and helped write the paper; $\mathrm{RH}$ wrote the protocol and paper, designed the questionnaires, performed the randomisation, supervised data collection and management, and designed the analyses; FO collected the data and managed the project; RG and AZ recruited patients, performed surgery, and helped manage the evaluation; TM conceived the study, wrote the protocol, and advised on analysis and interpretation; all authors contributed to and approved the final text.

\section{ACKNOWLEDGEMENTS}

The study was funded by the former Trent Regional NHS Research and Development scheme and the PPP Foundation (now the Health Foundation). Deborah Watmough and Jan Jones helped arrange data entry.

\section{Authors' affiliations}

R H Harwood*, Health Care of the Elderly, University Hospital, Queen's Medical Centre, Nottingham NG7 2UH, UK

A J E Foss*, F Osborn, R M Gregson, A Zaman, Department of Ophthalmology, University Hospital, Queen's Medical Centre, Nottingham NG7 2UH, UK 
T Masud, Clinical Gerontology Research Unit, City Hospital, Nottingham NG5 3PB, UK

*These authors made equal contributions.

Ethical approval: Granted by the Queens Medical Centre Ethics Committee.

\section{REFERENCES}

1 Masud T, Morris RO. Epidemiology of falls. Age and Ageing 2001;30(Suppl 4):3-7.

2 Campbell J. Falls. In: Ebrahim S, Kalache A, eds. Epidemiology of old age. London: BMJ Publications/WHO, 1996:361-8.

3 Ryynanen OP, Kivela SL, Honkanen R, et al. Incidence of falling injuries leading to medical treatment in the elderly. Public Health 1991;105:373-86.

4 Lord SR, McClean D, Stathers G. Physiological factors associated with injurious falls in older people living in the community. Gerontology 1992;38:338-46.

5 Nevitt MC, Cummings SR, the Study of Osteoporosis Fractures Research Group. Type of hip and wrist fractures: the study of osteoporotic fractures. J Am Geriatrics Soc 1993:41:1226-34.

6 Tinetti ME, Speechley M, Ginter SF. Risk factors for falls among elderly persons living in the community. N Engl J Med 1988;319:1701-7.

7 Nevitt MC, Cummings SR, Kidd S, et al. Risk factors for recurrent non-syncopal falls. a prospective study. JAMA 1989;261:2663-8.

8 Cummings SR, Nevitt MC, Browner WS, et al. Risk factors for hip fracture in white women. Study of Osteoporotic Fractures Research Group. N Engl J Med 1995;332:767-3.

9 Close J, Ellis $M$, Hooper R, et al. Prevention of falls in the elderly trial (PROFET): a randomised controlled trial. Lancet 1999;353:93-7.

10 Tinetti ME, Baker DI, McAvay G, et al. A multifactorial intervention to reduce the risk of falling among elderly people living in the community. N Engl J Med 1994;331:821-7.

11 NHS Centre for Reviews and Dissemination, York. Preventing falls and subsequent injury in older people. Effective Health Care 1996;2(4).

12 Harwood RH. Visual problems and falls. Age and Ageing 2001;30(Suppl 4): 13-18.

13 Dargent-Molina P, Favier F, Grandjean H, et al. Fall-related factors and risk of hip fracture: the EPIDOS prospective study. Lancet 1996;348:145-9.

14 Lord SR, Ward JA, Williams P, et al. Physiological factors associated with falls in older community-dwelling women. J Am Geriatrics Soc 1994;42:11 10-17.

15 Klein BE, Klein R, Lee KE, et al. Performance-based and self-assessed measures of visual function as related to history of falls, hip fractures, and measured gait time. The Beaver Dam Eye Study. Ophthalmology $1998 ; 105: 160-4$

16 Kelsey JL, Browner WS, Seeley DG, et al. Risk factors for fractures of the distal forearm and proximal humerus. The Study of Osteoporotic Fractures Research Group. Am J Epidemiol 1992;135:477-89.

17 Lord SR, Clark RD, Webster IW. Visual acuity and contrast sensitivity in relation to falls in an elderly population. Age and Ageing 1991;20:175-81.
18 Ivers RQ, Cumming RG, Mitchell $P$, et al. Visual impairment and falls in older adults: the Blue Mountains Eye Study. J Am Geriatrics Soc 1998;46:58-64. 19 Desai $\mathbf{P}$, Reidy A, Minassian DC, et al. Gains from cataract surgery: visual function and quality of life. Br J Ophthalmol 1996;80:868-73.

20 Prince M, Harwood RH, Blizard R, et al. Social support deficits, life events and loneliness as risk factors for late life depression. Psychol Med 1997;27:323-32.

21 Folstein MF, Folstein SE, McHugh PR. "Mini-mental state". A practical method for grading the cognitive state of patients for the clinician. J Psychiatr Res 1975; 12:189-98.

22 Voorrips LE, Ravelli ACJ, Dongelmans PCA, et al. A physical activity questionnaire for the elderly. Medicine and Science in Sports and Exercise $1991 ; 23: 974-9$.

23 Zigmond AS, Snaith RP. The hospital anxiety and depression scale. Acta Psychiatr Scand 1983;67:361-70.

24 Tinetti ME, Richman D, Powell L. Falls efficacy as a measure of fear of falling. J Gerontol 1990;45:239-43.

25 Wade DT, Collin C. The Barthel ADL Index: a standard measure of physical disability? International Disability Studies 1988;10:64-7.

26 Steinberg EP, Tielsch JM, Schein OD, et al. The VF-14. An index of functional impairment in patients with cataract. Arch Ophthalmol 1994;112:630-8.

27 Harwood RH, Ebrahim S. The Manual of the London handicap scale. Nottingham: University of Nottingham, 1995 (available from Dr Harwood).

28 Centre for Health Economics. Eurogol EQ-5D users guide. York: Centre for Health Economics, 1996.

29 Bailey IL, Lovie JE. New design principles for visual acuity letter charts. Am J Optom Physiol Opt 1976;53:740-5.

30 Pelli DG, Robson JG, Wilkins AJ. The design of a new letter chart for measuring contrast sensitivity. Clin Vis Sci 1988:2:187-99.

31 Kazis LE, Anderson JJ, Meenan RF. Effect sizes for interpreting changes in health status. Medical Care 1989;27(3 Suppl):S178-89.

32 Evans JG. Fallers, non-fallers and Poisson. Age and Ageing 1990;19:268-9.

33 Brannan S, Dewar C, Sen J, et al. A prospective study of the rate of falls before and after cataract surgery. Br J Ophthalmol 2003;87:560-2.

34 World Health Organization. International classification of impairments, disabilities and handicaps. Geneva: WHO, 1980.

35 World Health Organisation. International classification functioning, disability and health. Geneva: WHO, 2001. Available at www3.who.int/icf/ icftemplate.cfm (accessed 18 December 2003)

36 Reidy A, Minassian DC, Vafidis G, et al. Prevalence of serious eye disease and visual impairment in a north London population: population based, cross sectional study. BMJ 1998:316:1643-6.

37 Minassian DC Reidy A, Desai $P$, et al. The deficit in cataract surgery in England and Wales and the escalating problem of visual impairment: epidemiological modelling of the population dynamics of cataract. Br J Ophthalmol 2000;84:4-8.

38 Evans JR, Fletcher AE, Wormald RP, et al. Prevalence of visual impairment in people aged 75 years and older in Britain: results from the MRC trial of assessment and management of older people in the community. $\mathrm{Br} J$ Ophthalmol 2002;86:795-800.

39 American Geriatrics Society, British Geriatrics Society, American Academy of Orthopaedic Surgeons' Panel on Falls Prevention. Guideline for the prevention of falls in older persons. J Am Geriatrics Soc 2001;49:664-72. 